\title{
The moisture response of soil heterotrophic respiration: interaction with soil properties
}

\author{
F. E. Moyano ${ }^{1}$, N. Vasilyeva ${ }^{1}$, L. Bouckaert ${ }^{2}$, F. Cook $^{3}$, J. Craine ${ }^{4}$, J. Curiel Yuste ${ }^{5}$, A. Don ${ }^{6}$, D. Epron ${ }^{7}$, P. Formanek ${ }^{8}$, \\ A. Franzluebbers ${ }^{9}$, U. Ilstedt ${ }^{10}$, T. Kätterer ${ }^{11}$, V. Orchard ${ }^{12}$, M. Reichstein ${ }^{13}$, A. Rey $^{5}$, L. Ruamps ${ }^{1}$, J.-A. Subke ${ }^{14}$, \\ I. K. Thomsen ${ }^{15}$, and C. Chenu ${ }^{1}$ \\ ${ }^{1}$ CNRS-UPMC-AgroParisTech, UMR Bioemco 7618, 78850 Thiverval-Grignon, France \\ ${ }^{2}$ Department of soil management and soil care, Ghent University, Ghent, Coupure Links 653, Belgium \\ ${ }^{3}$ Environmental Physicist/Director, Freeman Cook \& Associates, Pty Ltd, P.O. Box 948, Mt Ommaney Q4074, Australia \\ ${ }^{4}$ Division of Biology, Kansas State University, Manhattan KS 66506-4901, USA \\ ${ }^{5}$ Museo Nacional de Ciencias Naturales CSIC, Serrano 115 dpdo, 28006 Madrid, Spain \\ ${ }^{6}$ Johann Heinrich von Thünen-Institut, Institut für Agrarrelevante Klimaforschung, Bundesallee 50, \\ 38116 Braunschweig, Germany \\ ${ }^{7}$ Nancy-Université, UMR Ecologie et Ecophysiologie Forestières, 54506 Vandoeuvre Les Nancy, France \\ ${ }^{8}$ Mendel University Brno, Department of Geology and Soil Science, Zemedelska 3, 61300 Brno, Czech Republic \\ ${ }^{9}$ USDA - Agricultural Research Service, 1420 Experiment Station Road, Watkinsville GA 30677, USA \\ ${ }^{10}$ Department of Forest Ecology and Management, SLU, SE-901 83 Umeå, USA \\ ${ }^{11}$ Professor, SLU, Dept. Soil and Environment, P.O. Box 7014, 75007 Uppsala, Sweden \\ ${ }^{12}$ Strategic Manager, Science and Research, ESR, New Zealand \\ ${ }^{13}$ Biogeochemical Model-Data Integration Group, Max-Planck Insititute for Biogeochemistry, 07701 Jena, Germany \\ ${ }^{14}$ University of Stirling, School of Natural Sciences, Biological and Environmental Sciences, Stirling FK9 4LA, Scotland, UK \\ ${ }^{15}$ Department of Agroecology, Organic Matter, Blichers Allé 20, 8830, Tjele, Denmark
}

Correspondence to: F. E. Moyano (fernando.moyano@grignon.inra.fr)

Received: 21 October 2011 - Published in Biogeosciences Discuss.: 2 December 2011

Revised: 5 February 2012 - Accepted: 12 March 2012 - Published: 28 March 2012

\begin{abstract}
Soil moisture is of primary importance for predicting the evolution of soil carbon stocks and fluxes, both because it strongly controls organic matter decomposition and because it is predicted to change at global scales in the following decades. However, the soil functions used to model the heterotrophic respiration response to moisture have limited empirical support and introduce an uncertainty of at least $4 \%$ in global soil carbon stock predictions by 2100 . The necessity of improving the representation of this relationship in models has been highlighted in recent studies. Here we present a data-driven analysis of soil moisture-respiration relations based on 90 soils. With the use of linear models we show how the relationship between soil heterotrophic respiration and different measures of soil moisture is consistently affected by soil properties. The empirical models derived include main effects and moisture interaction effects of soil texture, organic carbon content and bulk density. When
\end{abstract}

compared to other functions currently used in different soil biogeochemical models, we observe that our results can correct biases and reconcile differences within and between such functions. Ultimately, accurate predictions of the response of soil carbon to future climate scenarios will require the integration of soil-dependent moisture-respiration functions coupled with realistic representations of soil water dynamics.

\section{Introduction}

Soil moisture is one of the most important environmental factors driving productivity and carbon cycling in terrestrial ecosystems. Next to temperature, it is a primary determinant of the rate at which soil carbon is mineralized by microbes into carbon dioxide (Greaves and Carter, 1922; Davidson et al., 2000; Davidson and Janssens, 2006; Cook and Orchard, 
2008) and the main driver of soil microbial activity in many ecosystems (Davidson et al., 2000; Jassal et al., 2008; Liu et al., 2009). It is also expected to change significantly at global scales as a result of climate change in the coming decades (IPCC, 2007; Burke and Brown, 2010), potentially leading to large scale changes in soil carbon stocks in different regions, such as the Amazon basin (Falloon et al., 2011).

The relationship between soil moisture and soil respiration is known to be variable. It depends not only on the soil type (Franzluebbers, 1999; Vincent et al., 2006) but also on the diversity of measures used to express water conditions in soils, each having a unique relationship with soil microbial activity (Ilstedt et al., 2000; Paul et al., 2003). Soil factors including total pore space, bulk density and texture have been shown to influence this relationship (Franzluebbers, 1999; Thomsen et al., 1999). However, such studies have been few with most concentrating on finding the measure of moisture that best predicts respiration rates (e.g. water potential, water-filled pore space, etc.) or the single function that best describes this relationship (e.g. linear, polynomial, etc.). A systematic analysis of variations in response to a wide range of soil types has been lacking.

Soil carbon models use soil moisture-respiration functions that, in theory, represent an average response of microbial respiration to soil moisture content, i.e. they do not account for any possible variation in this relationship (Rodrigo et al., 1997). In addition, these functions are generally developed and validated using soils from specific sites and, as a consequence, are not suitable for a wider range of soil types. Accordingly, a few studies indicate that the variability in soil carbon budget predictions related to the use of different moisture-respiration functions can be important (Rodrigo et al., 1997; Bauer et al., 2008; Falloon et al., 2011). Fallon et al. (2011) showed that the divergence in simulations related to the choice of moisture function alone is nearly $4 \%$ of global carbon stocks by 2100 . However, since all the compared functions still represent an "average" response, the real uncertainty may be larger than reported. A better understanding of how this relationship actually depends on soil properties will help to quantify and reduce such uncertainties (Franzluebbers, 1999; Schjonning et al., 1999; Thomsen et al., 1999).

Here we present results from a meta-analysis of multiple soil incubation datasets that describe how soil properties regulate the relationship between soil microbial respiration and moisture. We use the terms "soil respiration" or simply "respiration" referring to soil $\mathrm{CO}_{2}$ emissions from heterotrophic microbial activity. The soil respiration response to moisture is the result of several processes - including osmotic stress, diffusion and oxygen limitations - that combined produce a net effect on the rate of carbon decomposition. Consequently, we did not look for a function that acts as the best single average predictor, as it would invariably underperform in most soil types. Instead, we treated the respiration response as a variable that changes freely at different levels of moisture and is explained by moisture itself and other soil properties.

The main outcome of this analysis is statistical models that predict the proportional response of soil respiration to moisture as a soil-type dependent variable. This can then be used to derive relative soil respiration curves for a given soil type. We illustrate the results by comparing the model we derive, using data from soils of England and Wales (Bellamy et al., 2005), with other currently used functions.

\section{Materials and methods}

\subsection{Data processing}

Data were assembled from studies where soil carbon dioxide emissions were measured together with variations in soil moisture under controlled laboratory conditions. Treatments varied across studies (e.g. intact vs. homogenized soils) but only homogenous samples with respect to soil properties were used. Incubations with temperatures outside the 10 to $35^{\circ} \mathrm{C}$ range were excluded. Respiration data from incubations where moisture decreased over time were corrected for substrate depletion effects using data from control (constant moisture) samples. Pore space, if not available, was calculated assuming a mineral density of 2.65 and organic matter density of 1.4 (Rühlmann et al., 2006). We converted the measures of soil $\mathrm{CO}_{2}$ emissions, moisture and soil properties to the same units and individually normalized soil respiration data sets to a $0-1$ scale. The latter facilitated data manipulation but did not affect the results since we analyzed the proportional response rather than the absolute changes, as described below.

The resulting database consisted of data from 90 different soils originating from 42 sites and characterized by a broad range of soil properties (Tables 1 and 2). From this data we obtained a total of 310 respiration-moisture relationships by plotting soil respiration from a given soil against related soil moisture data expressed in one or more out of four available measures. These measures are: mass related or gravimetric moisture $\left(\theta_{\mathrm{m}}\right)$, volumetric moisture $\left(\theta_{\mathrm{v}}\right)$, fraction of water saturation $\left(\theta_{\mathrm{s}}\right)$, and the logarithm of water potential $\left(\psi_{\log }\right) . \theta_{\mathrm{m}}$ is a laboratory standard while $\theta_{\mathrm{v}}$ is the most widely used field measure, often associated with high frequency carbon flux data. $\theta_{\mathrm{s}}$ and $\psi_{\log }$ are often considered optimal predictors of microbial respiration as they are related to air space and water energy status respectively (Orchard and Cook, 1983; Skopp et al., 1990). In order to obtain an approximate range of 0 to 1 , convenient for the analysis, the unit used for $\psi_{\log }$ was $\left(-\log _{10}|\psi|_{\mathrm{kPa}}\right) / 5+1$. Those for the other measures are: $\mathrm{g} \mathrm{H}_{2} \mathrm{O}$ gSoil ${ }^{-1}\left(\theta_{\mathrm{m}}\right), \mathrm{cm}^{3} \mathrm{H}_{2} \mathrm{O} \mathrm{cm}{ }^{-3}$ $\left(\theta_{\mathrm{V}}\right)$, and $\mathrm{cm}^{3} \mathrm{H}_{2} \mathrm{O} \mathrm{cm} \mathrm{cm}^{-3}$ pore-space $\left(\theta_{\mathrm{S}}\right)$. When possible, missing moisture measures were derived, e.g. using bulk density or pore space for converting $\theta_{\mathrm{v}}$ to $\theta_{\mathrm{m}}$ or $\theta_{\mathrm{s}}$, respectively, and vice versa. 
Table 1. Description of the data used in the analysis. Each line represents a specific site or location. DS is number of data sets, representing different soil types related to each site. Site averages of soil properties used in the analysis are shown. BD = bulk density, SOC $=$ soil organic carbon, $\mathrm{N}=$ soil nitrogen.

\begin{tabular}{|c|c|c|c|c|c|c|c|c|c|c|}
\hline Reference & DS & Country & Ecosystem & $\begin{array}{c}\mathrm{BD} \\
\left(\mathrm{g} \mathrm{cm}^{-3}\right)\end{array}$ & $\begin{array}{c}\mathrm{SOC} \\
\left(\mathrm{mg} \mathrm{g}^{-1}\right)\end{array}$ & $\begin{array}{c}\mathrm{N} \\
\left(\mathrm{mg} \mathrm{g}^{-1}\right)\end{array}$ & $\begin{array}{r}\text { Clay } \\
(\%)\end{array}$ & $\begin{array}{l}\text { Silt } \\
(\%)\end{array}$ & $\begin{array}{r}\text { Sand } \\
(\%)\end{array}$ & $\mathrm{pH}$ \\
\hline Bouckaert (unpublished data) & 3 & Belgium & Forest & 1.6 & 44 & 3.5 & 18 & 49 & 33 & 5.4 \\
\hline Bowden et al. (1998) & 1 & USA & Forest & 0.3 & NA & NA & NA & NA & NA & 3.3 \\
\hline Cook (unpublished data) & 1 & New Zealand & Grassland & 1.3 & 64 & 4.7 & 16 & 6 & 79 & 5.4 \\
\hline Cook (unpublished data) & 1 & New Zealand & Grassland & 0.9 & 55 & 5.5 & 17 & 33 & 50 & 5.7 \\
\hline Cook (unpublished data) & 1 & New Zealand & Grassland & 0.8 & 71 & 6.2 & 52 & 34 & 14 & 6.1 \\
\hline Cook et al. (1985) & 1 & New Zealand & Grassland & NA & NA & NA & NA & NA & NA & NA \\
\hline Craine and Gelderman (2011) & 8 & USA & Grassland & NA & 46 & 3.3 & 33 & 60 & 8 & 6.7 \\
\hline Curiel Yuste et al. (2007) & 2 & USA & Forest & 0.9 & 102 & 3.5 & 11 & 29 & 60 & 5.5 \\
\hline Curiel Yuste et al. (2007) & 2 & USA & Grassland & 1.5 & 28 & 2.5 & 14 & 44 & 43 & 6.4 \\
\hline Don (unpublished data) & 1 & Germany & Grassland & 1.5 & 11 & 1.1 & 9 & 10 & 81 & 4.5 \\
\hline Doran (1990) & 1 & USA & Forest & 1.1 & 31 & NA & 14 & 16 & 70 & 6.8 \\
\hline Doran (1990) & 1 & USA & Cultivated & 1.2 & 14 & NA & 18 & 29 & 53 & 6.8 \\
\hline Doran (1990) & 1 & USA & Cultivated & 1.1 & 21 & NA & 22 & 75 & 3 & 6.8 \\
\hline Doran (1990) & 1 & USA & Grassland & 1.2 & 8 & NA & 26 & 19 & 55 & 6.8 \\
\hline Doran (1990) & 1 & USA & Grassland & 1.1 & 22 & NA & 17 & 64 & 19 & 6.8 \\
\hline Doran (1990) & 1 & USA & Grassland & 1.0 & 16 & NA & 46 & 42 & 12 & 6.8 \\
\hline Doran (1990) & 1 & USA & NA & 1.1 & 35 & NA & 14 & 37 & 49 & 6.8 \\
\hline Doran (1990) & 1 & USA & Cultivated & 1.2 & 13 & NA & 20 & 51 & 29 & 6.8 \\
\hline Doran (1990) & 1 & USA & Grassland & 1.2 & 7 & NA & 22 & 24 & 54 & 6.8 \\
\hline Doran (1990) & 1 & USA & Cultivated & 1.1 & 13 & NA & 58 & 35 & 7 & 6.8 \\
\hline Doran (1990) & 1 & USA & Cultivated & 1.1 & 11 & NA & 16 & 68 & 16 & 6.8 \\
\hline Skopp et al. (1990) & 1 & USA & Grassland & 1.2 & 13 & NA & 24 & 54 & 22 & 6.8 \\
\hline Epron (unpublished data) & 1 & France & Forest & 0.8 & 27 & 2.5 & 20 & 66 & 14 & 4.6 \\
\hline Formanek (unpublished data) & 3 & Czech Republic & Forest & NA & 318 & 11.2 & NA & NA & NA & 4.8 \\
\hline Franzluebbers (1999) & 15 & USA & Grassland & 1.2 & 16 & 1.1 & 19 & 16 & 65 & 6.2 \\
\hline Gulledge and Schimel (1998) & 2 & USA & Grassland & NA & 61 & NA & NA & NA & NA & NA \\
\hline Ilstedt et al. (2000) & 3 & Malaysia & Forest & 0.6 & 52 & 4.1 & 27 & 32 & 42 & 4.7 \\
\hline Ilstedt et al. (2000) & 1 & Sweden & Forest & 0.5 & 556 & NA & NA & NA & NA & 4.1 \\
\hline Linn and Doran (1984) & 1 & USA & Cultivated & NA & 21 & 1.6 & 34 & 54 & 12 & 5.8 \\
\hline Liu et al. (2009) & 1 & China & Grassland & NA & 16 & 1.5 & 17 & 20 & 63 & 6.8 \\
\hline Lomander et al. (1998) & 2 & Sweden & Cultivated & NA & 18 & 1.9 & 57 & 38 & 5 & 8.2 \\
\hline Nyhan (1976) & 1 & USA & NA & 1.4 & 9 & NA & NA & NA & NA & 6.8 \\
\hline Orchard and Cook (1983) & 1 & New Zealand & Grassland & NA & NA & NA & NA & NA & NA & NA \\
\hline Orchard et al. (1992) & 1 & New Zealand & Grassland & NA & 56 & 3.5 & 24 & NA & NA & 5.2 \\
\hline Orchard et al. (1992) & 1 & New Zealand & Grassland & NA & NA & NA & NA & NA & NA & NA \\
\hline Reichstein et al. (2005) & 1 & Germany & Forest & 0.9 & 45 & 2.0 & 10 & 38 & 52 & 2.9 \\
\hline Rey et al. (2005) & 2 & Italy & Forest & 1.0 & 49 & 6.0 & NA & NA & NA & 5.7 \\
\hline Ruamps (unpublished data) & 1 & France & Cultivated & 1.5 & 14 & 1.2 & 17 & 53 & 30 & 6.8 \\
\hline Thomsen et al. (1999) & 15 & Denmark & Cultivated & 1.3 & 15 & 1.5 & 23 & 14 & 64 & 6.9 \\
\hline Skopp et al. (1990) & 1 & USA & Cultivated & 1.4 & 9 & NA & 3 & 7 & 90 & 6.8 \\
\hline Stott et al. (1986) & 1 & USA & Cultivated & NA & 4 & 0.6 & NA & NA & NA & 7.0 \\
\hline Wickland and Neff (2008) & 3 & USA & Forest & NA & 318 & 14.5 & NA & NA & NA & NA \\
\hline
\end{tabular}

The following analysis was performed in parallel for each moisture measure using the $\mathrm{R}$ statistical software version 2.13.1 (Supplement: R Code and data files MRD.txt, DD.txt and funs.txt). We started by assuming that a response to a change in soil moisture is proportional to the value of respiration itself, as normally done in soil carbon models. By using the proportional response we make our results generalizable, avoiding the problem of comparing absolute respi- ration values which vary largely across soils. Since the response of respiration varies along the moisture axis, we defined the Proportional Response of Soil Respiration $\left(\mathrm{PR}_{\mathrm{SR}}\right)$ related to a 0.01 increase in soil moisture as the central unit for analysis, with the unit of this 0.01 value depending on the moisture measure applied. We then tested how $\mathrm{PR}_{\mathrm{SR}}$ is affected by diverse soil properties. 
Table 2. Range of values for soil moisture (SM), soil organic carbon (SOC), clay, and bulk density (BD) used to fit linear regression models using different measures of soil moisture. Numbers in italics are for descriptive purposes only since the respective variables were not used in that particular model. $\theta_{\mathrm{m}}$ is gravimetric moisture $\left(\mathrm{g} \mathrm{H}_{2} \mathrm{O}\right.$ gSoil $\left.{ }^{-1}\right), \theta_{\mathrm{v}}$ is volumetric moisture $\left(\mathrm{cm}^{3} \mathrm{H}_{2} \mathrm{O} \mathrm{cm}{ }^{-3}\right), \theta_{\mathrm{S}}$ is relative water saturation $\left(\mathrm{cm}^{3} \mathrm{H}_{2} \mathrm{O} \mathrm{cm}{ }^{-3}\right.$ pore-space), and $\Psi \log$ is water potential $[(-\log 10|\Psi| \mathrm{kPa}) / 5+1]$.

\begin{tabular}{|c|c|c|c|c|c|c|c|c|}
\hline \multirow{2}{*}{$\begin{array}{l}\text { Model and } \\
\text { Moisture Measure }\end{array}$} & \multicolumn{2}{|c|}{ SM } & \multicolumn{2}{|c|}{ SOC ( $\mathrm{g} \mathrm{g}^{-1}$ soil $)$} & \multicolumn{2}{|c|}{ Clay (fraction) } & \multicolumn{2}{|c|}{$\mathrm{BD}\left(\mathrm{g} \mathrm{cm}^{-3}\right)$} \\
\hline & $\min$ & $\max$ & $\min$ & $\max$ & $\min$ & $\max$ & $\min$ & $\max$ \\
\hline \multicolumn{9}{|c|}{ Model 1 (mineral soils) } \\
\hline$\theta_{\mathrm{m}}$ & 0.04 & 0.65 & 0.01 & 0.05 & 0.09 & 0.45 & 0.8 & 1.5 \\
\hline$\theta_{\mathrm{v}}$ & 0.05 & 0.60 & 0.01 & 0.05 & 0.03 & 0.58 & 0.8 & 1.5 \\
\hline$\theta_{\mathrm{s}}$ & 0.07 & 1.00 & 0.01 & 0.05 & 0.03 & 0.58 & 0.8 & 1.5 \\
\hline$\psi_{\log }$ & 0.22 & 1.02 & 0.01 & 0.03 & 0.09 & 0.45 & 0.6 & 1.5 \\
\hline \multicolumn{9}{|c|}{ Model 2 (mineral soils) } \\
\hline$\theta_{\mathrm{m}}$ & 0.04 & 0.66 & 0.01 & 0.05 & 0.09 & 0.57 & - & - \\
\hline$\theta_{\mathrm{v}}$ & 0.05 & 0.60 & 0.01 & 0.05 & 0.03 & 0.58 & - & - \\
\hline$\theta_{\mathrm{s}}$ & 0.07 & 1.00 & 0.01 & 0.05 & 0.03 & 0.58 & - & - \\
\hline$\psi_{\log }$ & 0.22 & 1.02 & 0.01 & 0.03 & 0.09 & 0.45 & - & - \\
\hline \multicolumn{9}{|c|}{ Model 3 (organic soils) } \\
\hline$\theta_{\mathrm{m}}$ & 0.05 & 1.1 & 0.05 & 0.40 & - & - & - & - \\
\hline$\theta_{\mathrm{V}}$ & 0.05 & 0.85 & 0.06 & 0.35 & - & - & 0.24 & 0.9 \\
\hline$\theta_{\mathrm{s}}$ & 0.07 & 0.99 & 0.06 & 0.35 & - & - & 0.24 & 0.9 \\
\hline$\psi_{\log }$ & 0.27 & 0.97 & 0.06 & 0.56 & - & - & - & - \\
\hline
\end{tabular}

To obtain $\mathrm{PR}_{\mathrm{SR}}$ values we used general additive models (GAMs) to fit smooth curves to each of the 310 relationships. Linear or polynomial fits were used instead if the number of moisture points in a dataset was less than 4 . Respiration values at each 0.01 moisture interval were then predicted from the fitted curves between the minimum and maximum moisture value of each relationship (as to avoid extrapolations). With the resulting set of predicted values, the $\mathrm{PR}_{\mathrm{SR}}$ of each 0.01 increase in moisture was calculated, at moisture $M$, as the average of $\operatorname{SR}(M) / \mathrm{SR}(M-0.01)$ and $\operatorname{SR}(M+0.01) / \operatorname{SR}(M)$.

\subsection{Regression models}

The dependence of $\mathrm{PR}_{\mathrm{SR}}$ on soil properties was analyzed using soil pore space, bulk density, soil organic carbon, and sand, silt and clay content. We also tested soil $\mathrm{pH}$ and the interaction between organic carbon and clay but found no significant effects. To isolate the effect of each soil property we used linear regression models of the form:

$\mathrm{PR}_{\mathrm{SR}}=\beta_{1} M+\beta_{2} M^{2}+\beta_{3} M^{3}+\beta_{i} \mathrm{SP}_{i}+\beta_{i} M \cdot \mathrm{SP}_{i}+\varepsilon$

where $M$ is soil moisture (either $\theta_{\mathrm{m}}, \theta_{\mathrm{v}}, \theta_{\mathrm{S}}$ or $\psi_{\mathrm{log}}$ ) and SP are soil properties which can interact with $M$. Stepwise model selection was applied.
Preliminary results revealed important differences between soils with high and low organic carbon content. After empirically testing the influence of different soils on the models' root mean square deviation, we set a threshold of $50 \mathrm{mg} \mathrm{C} \mathrm{g}^{-1}$ soil, with soils above this value considered organic for the purpose of this analysis. These soils were analyzed separately from mineral soils.

The $\mathrm{PR}_{\mathrm{SR}}$ tended to be very large at respiration values near 0 . Such $\mathrm{PR}_{\mathrm{SR}}$ are related to very low respiration rates and do not have a large absolute impact, but can still represent a real response. However, our model failed to accurately predict them and, as a consequence, a few of such values produced a strong general bias. To avoid this we excluded any $\mathrm{PR}_{\mathrm{SR}}$ value further than 3 standard deviations from the mean.

Model simplification led to excluding pore space (strongly correlated with BD), sand, silt and the SOC-M interaction. As bulk density is often not available for use in large scale soil simulations, we fitted a second model for mineral soils including only clay and organic carbon. The final linear models predicting $\mathrm{PR}_{\mathrm{SR}}$ were:

$$
\begin{aligned}
\mathrm{PR}_{\mathrm{SR}} & =\beta_{1} M+\beta_{2} M^{2}+\beta_{3} M^{3}+\beta_{4} \mathrm{BD} \\
& +\beta_{5} M \cdot \mathrm{BD}+\beta_{6} \text { clay }+\beta_{7} M \cdot \text { clay }+\beta_{8} \mathrm{SOC}
\end{aligned}
$$

$$
\begin{aligned}
\mathrm{PR}_{\mathrm{SR}} & =\beta_{1} M+\beta_{2} M^{2}+\beta_{3} M^{3}+\beta_{4} \text { clay } \\
& +\beta_{5} M \cdot \text { clay }+\beta_{6} \mathrm{SOC}
\end{aligned}
$$


$\mathrm{PR}_{\mathrm{SR}}=\beta_{1} M+\beta_{2} M^{2}+\beta_{3} M^{3}$

where $M$ is soil moisture, BD is bulk density, SOC is soil organic carbon and $\beta$ are model coefficients. Model 1 (Eq. 2) and Model 2 (Eq. 3) are mineral soil models, with the latter excluding bulk density (Table 3). Model 3 (Eq. 4) is for organic soils and has only moisture as a predictor. Few datasets were available for these soils and significant correlations with soil properties were not found (Table 3).

\subsection{Soil respiration predictions}

With the PR $\mathrm{SR}_{\mathrm{S}}$ values obtained from the above models, respiration was predicted using the equation:

$\mathrm{SR}(M)=\left(\Pi_{k=M_{0}}^{M} \mathrm{PR}_{\mathrm{SR}_{\mathrm{k}}}\right) \cdot \mathrm{SR}_{0}$

where soil respiration (SR) as a function of soil moisture $(M)$ is equal to an initial respiration value $\left(\mathrm{SR}_{0}\right)$ multiplied by the product of all $\mathrm{PR}_{\mathrm{SR}}$ values (denoted by the $\Pi$ symbol) at each 0.01 moisture interval $(k)$ from the initial moisture $\left(M_{0}\right)$ to $M$ (for $M_{0}<M$; otherwise the product term divides $\mathrm{SR}_{0}$ ). $\mathrm{PR}_{\mathrm{SR}}$ values at each $k$ interval are predicted with the above $\mathrm{PR}_{\mathrm{SR}}$ models.

Relative respiration curves, which scale respiration from 0 to 1 , were obtained in a two-step calculation: (1) using Eq. (2) to predict $\mathrm{PR}_{\mathrm{SR}}$ values for each 0.01 moisture interval and (2) using Eq. (5) to calculate respiration values along the moisture axis (with an arbitrary $\mathrm{SR}_{0}$ of 1 ) and dividing all values by the maximum obtained. As data at low moistures extremes was generally missing, regression models did not well reproduce the high $\mathrm{PR}_{\mathrm{SR}}$ related to respiration values approaching 0 . As a result, depending on the soil type, curve intercepts were variably higher than 0 . To obtain curves with a 0 intercept we applied a rescaling of respiration from 0 to 1 in the range of 0 to optimum moisture. For this, we subtracted the minimum respiration value $\left(R_{\min }\right)$ and divided by 1- $R_{\min }$ (Supplement: $\mathrm{R}$ Code lines 463-467). This resulted in a scaling down that was strongest at lower moisture levels but minimal when approaching optimal moisture.

In order to compare our results with existing functions, we applied Eq. (3) using $\theta_{\mathrm{s}}$ or $\psi_{\log }$ to predict respiration curves for 106 soil series from England and Wales covering an area of ca. $50000 \mathrm{~km}^{2}$. Soil organic carbon and clay content in these soils ranged between $0.01-0.05 \mathrm{~g} \mathrm{~g}^{-1}$ and 80 $610 \mathrm{~g}$ clay $\mathrm{kg}^{-1}$ soil. We compared these results with functions from six other models using the same moisture measures, plotting the resulting range of respiration values next to $\theta_{\mathrm{s}}$ functions belonging to the RothC (Coleman and Jenkinson, 1999; Bauer et al., 2008), CANDY (Franko et al., 1995; Powlson et al., 1996), Bethy (Knorr, 2000) and SimCycle (Ito and Oikawa, 2002) models and $\psi_{\log }$ functions from the Daisy (Abrahamsen and Hansen, 2000; Bauer et al., 2008) and SOILCO2 (Šimunek and Suarez, 1993; Bauer et al., 2008) models. To use $\theta_{\mathrm{S}}$ with the RothC function we followed the same procedure as Bauer et al. (2008), assuming

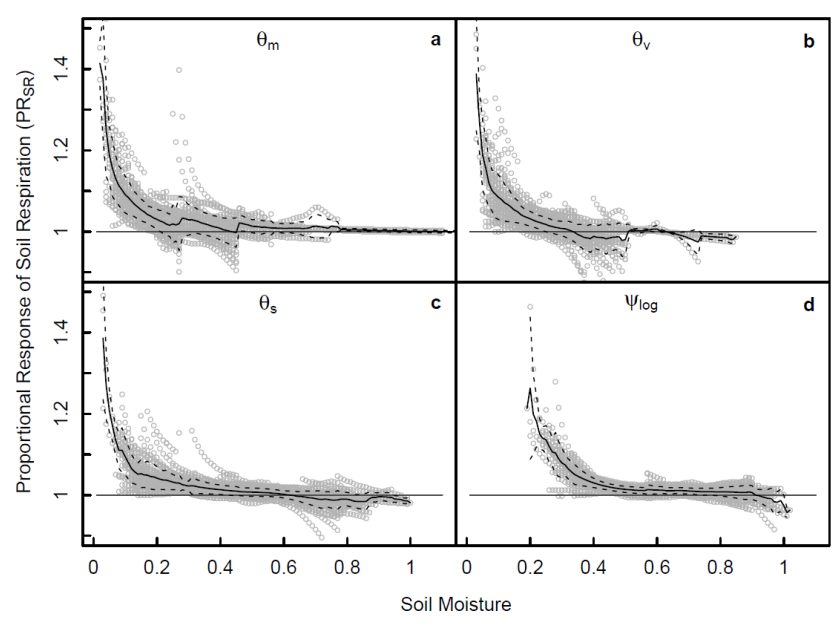

Fig. 1. Proportional response of soil microbial respiration $\left(\mathrm{PR}_{\mathrm{SR}}\right)$ to moisture. $\mathrm{PR}_{\mathrm{SR}}$ values correspond to a 0.01 increase in soil moisture. Values are shown for all datasets and for $\theta_{\mathrm{m}}$ (gravimetric moisture, (a)), $\theta_{\mathrm{v}}$ (volumetric moisture, (b)), $\theta_{\mathrm{S}}$ (fraction of saturation, (c)), and $\psi_{\log }(\log$ water potential , (d)). Units of soil moisture in the $\mathrm{x}$-axis are: $\mathrm{g} \mathrm{H}_{2} \mathrm{O} \mathrm{gSoil}^{-1}$ (a), $\mathrm{cm}^{3} \mathrm{H}_{2} \mathrm{O} \mathrm{cm} \mathrm{cm}^{-3}$ (b), $\mathrm{cm}^{3}$ $\mathrm{H}_{2} \mathrm{O} \mathrm{cm}^{-3}$ pore-space (c) and $\left(-\log _{10}|\psi|_{\mathrm{kPa}}\right) / 5+1$ (d). Grey circles represent the $\mathrm{PR}_{\mathrm{SR}}$ of each 0.01 moisture increase. The black and dashed lines are mean and standard deviations, respectively.

that the accumulated total soil moisture deficit equals $\theta_{\mathrm{v}}$ at saturation minus actual $\theta_{\mathrm{v}}$ and maximum total soil moisture deficit is equal to $\theta_{\mathrm{v}}$ at saturation.

\section{Results}

For each dataset, $\mathrm{PR}_{\mathrm{SR}}$ values are highest at dry conditions and decrease progressively with increasing moisture (Fig. 1), with values below 1 corresponding to a negative trend in respiration rates. Mean $\mathrm{PR}_{\mathrm{SR}}$ values for $\theta_{\mathrm{S}}$ and $\psi_{\log }$ decreased monotonically with increasing moisture (Fig. 1c and d) while those for $\theta_{\mathrm{m}}$ and $\theta_{\mathrm{v}}$ showed more discontinuities related to sharp variations in soil types (Fig. 1a and b). All moisture measures had a wide range of soil moisture associated to an optimum for respiration, defined as the point where $\mathrm{PR}_{\mathrm{SR}}$ crosses 1 . Taking $\theta_{\mathrm{S}}$ as an example, the $\mathrm{PR} \mathrm{SR}$ mean value reaches 1 at $0.63 \theta_{\mathrm{s}}$, consistent with the commonly reported range of $0.6-0.7$, but different datasets had values of optimum moisture as low as 0.4 and as high as 0.9 water saturation.

For mineral soils, significant correlations were found between $\mathrm{PR}_{\mathrm{SR}}$ and all soil properties, with the correlation strength and significance being strongly dependent on the moisture range and type of moisture measure (Fig. 2). With $\theta_{\mathrm{m}}$ and $\theta_{\mathrm{v}}$, correlation coefficients of $\mathrm{PR}_{\mathrm{SR}}$ versus bulk density were negative and tended to increase with increasing moisture. Correlations with pore space, not shown in Fig. 2, were identical but of opposite sign, i.e. positive. Fewer or no 
Table 3. Variables and coefficients for linear models predicting the proportional response of soil respiration $\left(\mathrm{PR}_{\mathrm{SR}}\right)$ at 0.01 moisture intervals. $\mathrm{SM}=$ soil moisture, $\mathrm{BD}=$ bulk density, $\mathrm{SOC}=$ soil organic carbon. Coefficient values and standard errors are given under the corresponding moisture measure. All terms are significant at $p<0.001$. In addition, values are given for the number of data points $(n)$ and datasets used, and the model root mean square deviation (RMSD) with the improvement relative to a moisture-only fit in brackets.

\begin{tabular}{|c|c|c|c|c|}
\hline Variables & $\begin{array}{r}\text { Gravimetric } \\
\text { moisture }\left(\theta_{\mathrm{m}}\right)\end{array}$ & $\begin{array}{r}\text { Volumetric } \\
\text { moisture }\left(\theta_{\mathrm{V}}\right)\end{array}$ & $\begin{array}{r}\text { Fraction of } \\
\text { saturation }\left(\theta_{\mathrm{s}}\right)\end{array}$ & $\begin{array}{r}\text { Log water } \\
\text { potential }\left(\psi_{\log }\right)\end{array}$ \\
\hline \multicolumn{5}{|c|}{ Model 1 (mineral soils) } \\
\hline$n$ & 1233 & 1936 & 3610 & 2193 \\
\hline$n$-datasets & 50 & 52 & 52 & 42 \\
\hline RMSD & $0.023(0.006)$ & $0.024(0.003)$ & $0.014(0.002)$ & $0.012(0.001)$ \\
\hline Intercept & $1.00 \pm 0.02$ & $0.98 \pm 0.01$ & $1.02 \pm 0.00$ & $1.26 \pm 0.02$ \\
\hline SM & $-0.80 \pm 0.09$ & $-0.48 \pm 0.08$ & $-0.29 \pm 0.02$ & $-1.36 \pm 0.05$ \\
\hline$(\mathrm{SM})^{2}$ & $3.5 \pm 0.2$ & $1.8 \pm 0.3$ & $0.37 \pm 0.04$ & $2.26 \pm 0.08$ \\
\hline$(\mathrm{SM})^{3}$ & $-3.1 \pm 0.2$ & $-1.6 \pm 0.3$ & $-0.19 \pm 0.03$ & $-1.12 \pm 0.04$ \\
\hline $\mathrm{BD}\left(\mathrm{g} \mathrm{cm}^{-3}\right)$ & $0.10 \pm 0.01$ & $0.1 \pm 0.01$ & $0.03 \pm 0.00$ & $0.05 \pm 0.01$ \\
\hline $\mathrm{BD}\left(\mathrm{g} \mathrm{cm}^{-3}\right) \mathrm{SM}$ & $-0.44 \pm 0.05$ & $-0.3 \pm 0.04$ & - & $-0.09 \pm 0.01$ \\
\hline Clay (fraction) & $0.33 \pm 0.03$ & $0.18 \pm 0.02$ & $0.09 \pm 0.01$ & $0.17 \pm 0.02$ \\
\hline Clay (fraction) SM & $-0.7 \pm 0.1$ & $-0.31 \pm 0.06$ & $-0.08 \pm 0.01$ & $-0.25 \pm 0.02$ \\
\hline SOC $\left(\right.$ g gSoil $\left.^{-1}\right)$ & $1.5 \pm 0.1$ & $1.4 \pm 0.09$ & $0.8 \pm 0.04$ & - \\
\hline \multicolumn{5}{|c|}{ Model 2 (mineral soils) } \\
\hline$n$ & 1474 & 1951 & 3710 & 2232 \\
\hline$n$-datasets & 59 & 65 & 66 & 43 \\
\hline RMSD & $0.025(0.006)$ & $0.025(0.002)$ & $0.015(0.001)$ & $0.013(0.0003)$ \\
\hline Intercept & $1.13 \pm 0.01$ & $1.11 \pm 0.01$ & $1.059 \pm 0.003$ & $1.31 \pm 0.01$ \\
\hline SM & $-1.31 \pm 0.05$ & $-0.83 \pm 0.07$ & $-0.26 \pm 0.02$ & $-1.45 \pm 0.05$ \\
\hline$(\mathrm{SM})^{2}$ & $3.0 \pm 0.2$ & $1.5 \pm 0.3$ & $0.32 \pm 0.04$ & $2.18 \pm 0.08$ \\
\hline$(\mathrm{SM})^{3}$ & $-2.23 \pm 0.2$ & $-1.0 \pm 0.3$ & $-0.15 \pm 0.03$ & $-1.07 \pm 0.04$ \\
\hline Clay (fraction) & $0.26 \pm 0.02$ & $0.08 \pm 0.01$ & $0.08 \pm 0.01$ & $0.12 \pm 0.01$ \\
\hline Clay (fraction) SM & $-0.39 \pm 0.05$ & - & $-0.09 \pm 0.01$ & $-0.16 \pm 0.02$ \\
\hline SOC $\left(\right.$ g gSoil $\left.^{-1}\right)$ & $1.07 \pm 0.07$ & $1.28 \pm 0.08$ & $0.57 \pm 0.04$ & $0.19 \pm 0.06$ \\
\hline \multicolumn{5}{|c|}{ Model 3 (organic soils) } \\
\hline$n$ & 682 & 286 & 355 & 159 \\
\hline$n$-datasets & 16 & 6 & 6 & 3 \\
\hline RMSD & 0.020 & 0.010 & 0.008 & 0.014 \\
\hline Intercept & $1.146 \pm 0.005$ & $1.178 \pm 0.004$ & $1.134 \pm 0.003$ & $1.42 \pm 0.04$ \\
\hline SM & $-0.57 \pm 0.03$ & $-1.12 \pm 0.03$ & $-0.67 \pm 0.02$ & $-1.9 \pm 0.2$ \\
\hline$(\mathrm{SM})^{2}$ & $0.79 \pm 0.07$ & $2.22 \pm 0.09$ & $1.08 \pm 0.05$ & $2.9 \pm 0.4$ \\
\hline$(\mathrm{SM})^{3}$ & $-0.37 \pm 0.04$ & $-1.40 \pm 0.06$ & $-0.57 \pm 0.03$ & $-1.4 \pm 0.2$ \\
\hline
\end{tabular}

significant correlations of these properties were seen for $\theta_{\mathrm{s}}$ and $\psi_{\log }$.

Significant $\mathrm{PR}_{\mathrm{SR}}$ correlations with texture and organic carbon were found for all moisture measures but most importantly for $\theta_{\mathrm{m}}$ and $\theta_{\mathrm{v}}$. Correlations were generally negative for sand and positive for clay, silt and organic carbon. Correlations with clay and silt followed a similar pattern that mirrored the behavior of sand. Correlations with organic carbon content were similar to those of clay and silt. In contrast, organic soils showed no significant correlations between $\mathrm{PR}_{\mathrm{SR}}$ and carbon content (data not shown).
The range of values used for fitting the multiple linear regression models is given in Table 2. Models using $\theta_{\mathrm{m}}$ and $\theta_{\mathrm{v}}$ showed the largest improvement in their root mean square deviation (RMSD) after adding soil properties to the basic moisture polynomial. However, the much lower RMSD values of the models using $\theta_{\mathrm{s}}$ and $\psi_{\log }$, which only decreased slightly after adding soil properties, show that they are better predictors, with $\psi_{\log }$ having a slightly better performance (Table 3). An analysis of model residuals resulted in no trend or significant correlation with soil incubation temperature and incubation duration. Note that models using different measures of moisture were fitted with different sets 

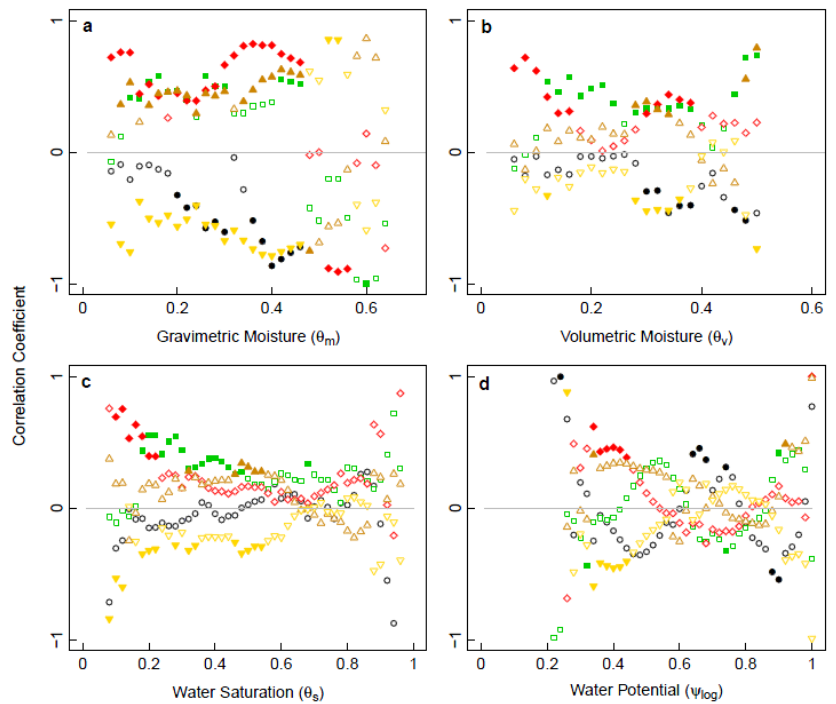

Fig. 2. The respiration response to moisture $\left(\mathrm{PR}_{\mathrm{SR}}\right)$ correlated with soil properties of mineral soils. Correlation coefficients of $\mathrm{PR}_{\mathrm{SR}}$ vs. bulk density (black circles), organic carbon (green squares), sand (yellow inverted triangles), silt (brown triangles) and clay (red diamonds) on the y-axis are shown for different levels of soil moisture (SM) on the $\mathrm{x}$-axis. Full symbols denote correlations significant at $p<0.05$. Units of soil moisture in the $\mathrm{x}$-axis are: $\mathrm{g} \mathrm{H}_{2} \mathrm{O}$ gSoil $^{-1}$ (a), $\mathrm{cm}^{3} \mathrm{H}_{2} \mathrm{O} \mathrm{cm}{ }^{-3}$ (b), $\mathrm{cm}^{3} \mathrm{H}_{2} \mathrm{O} \mathrm{cm} \mathrm{cm}^{-3}$ pore-space (c) and $\left[-\log _{10}|\psi|_{\mathrm{kPa}}\right] / 5+1(\mathbf{d})$.

of observations, one reason why $R^{2}$ values were not used to compare them.

Relative respiration curves are shown in Fig. 3. The effect of clay content on respiration was mainly at low (aerobic) moisture ranges and strongly affected the spread in the curve. Less clay resulted in a wider range of soil moisture values associated to optimal respiration and a respiration peak at lower water contents. Soil organic carbon produced a shift in the curve under all moisture measures with the exception of water potential. More carbon content did not affect the spread of the curve but drove the point of maximum respiration towards higher values of moisture. With changes in bulk density, respiration changed relatively little for a constant volumetric moisture ( $\theta_{\mathrm{v}}$ curve) or water potential ( $\psi_{\log }$ curve) but changed strongly under a constant gravimetric moisture $\left(\theta_{\mathrm{m}}\right.$ curve) or water saturation fraction $\left(\theta_{\mathrm{S}}\right.$ curve).

When compared to currently used models (Fig. 4), results from our model covered much of the range of variability between other functions based on $\theta_{\mathrm{s}}$, which either underor overestimate average respiration, with a strong tendency towards the latter. Functions using $\psi_{\log }$ were comparable to our predictions, where we observed a limited influence of soil properties, but they showed a general overestimation of respiration values in most of the range of suboptimal moisture conditions.

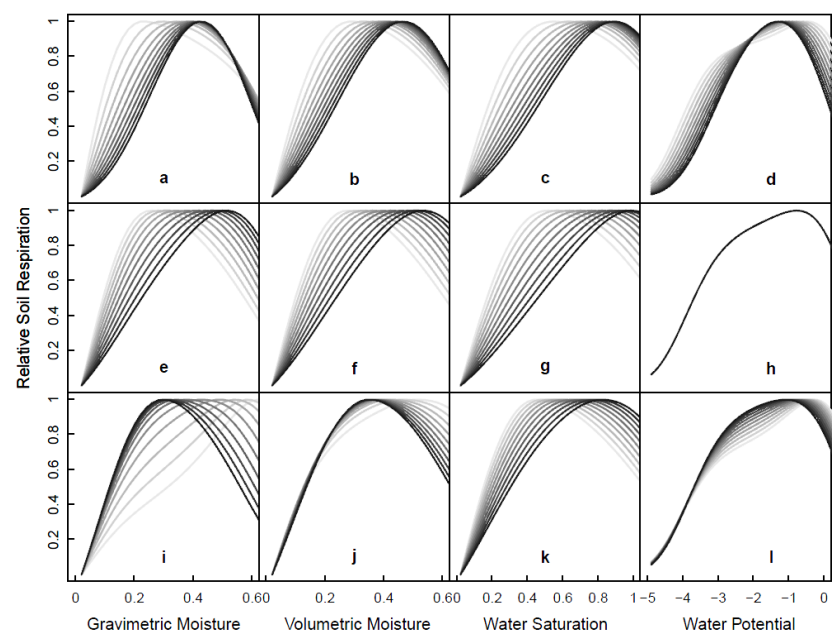

Fig. 3. The response of predicted soil moisture-respiration curves to variations in soil properties for mineral soils. Darker lines represent higher values of a given property. Variations are shown for clay content from 0.1 to 1 fraction $(\mathbf{a}-\mathbf{d})$, organic carbon from 0.005 to $0.05 \mathrm{~g} \mathrm{~g}^{-1}(\mathbf{e}-\mathbf{h})$, and bulk density from 0.6 to $1.6 \mathrm{~g} \mathrm{~cm}^{-3}(\mathbf{i}-\mathbf{l})$. The respective values for the variables held constant are: 0.3 fraction, $0.02 \mathrm{~g} \mathrm{~g}^{-1}$ and $1.2 \mathrm{~g} \mathrm{~cm}^{-3}$. Moisture units are: $\mathrm{g} \mathrm{H}_{2} \mathrm{O} \mathrm{gSoil}^{-1}$ (a, e, i) $\mathrm{cm}^{3} \mathrm{H}_{2} \mathrm{O} \mathrm{cm}{ }^{-3}(\mathbf{b}, \mathbf{f}, \mathbf{j}), \mathrm{cm}^{3} \mathrm{H}_{2} \mathrm{O} \mathrm{cm}{ }^{-3}$ pore-space $(\mathbf{c}, \mathbf{g}, \mathbf{k})$, and $-\log _{10}|\psi|_{\mathrm{kPa}}(\mathbf{d}, \mathbf{f}, \mathbf{l})$.

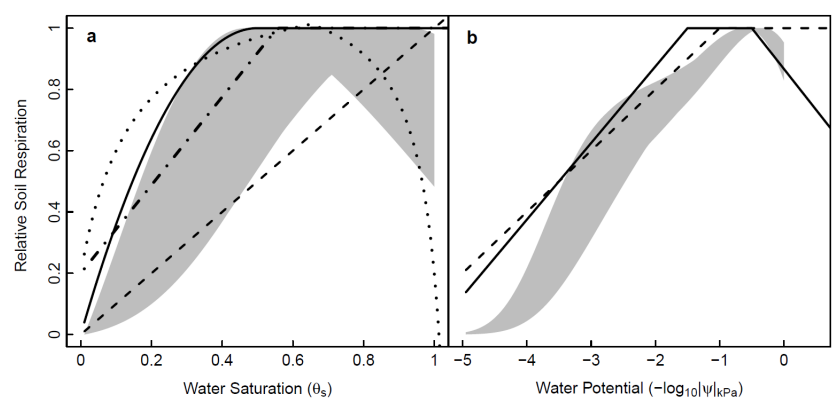

Fig. 4. Comparison of predicted relative soil heterotrophic respiration as a function of soil moisture. The grey area marks the full range of values obtained with Eqs. (3) and (5) using $\theta$ s (a) or $\psi \mathrm{log}$ (b) for 106 soil series from England and Wales ranging from 8 to $50 \mathrm{mg} \mathrm{g}^{-1}$ SOC and 0.08 to 0.61 clay fraction. Other lines are moisture-respiration functions from existing models using either $\theta \mathrm{s}$ (a) or $\psi \log$ (b) as a predictor. (a): CANDY model (full line), Bethy model (dashed line), SimCycle model (dotted line), RothC model (dot-dash line). (b): Daisy model (full line), SOILCO2 model (dashed line).

\section{Discussion}

This comparison of multiple datasets revealed a strong soildependent variation of the moisture-respiration relationship, in clear contrast to the simple functions found in all current models. The large range of variability observed (e.g. respiration maximums ranging from $40-100 \%$ water saturation) 
reflects differences between ecosystems that are largely ignored in the more common and simplified representations of this relationship. A major difference observed was in the response of organic vs. mineral soils. In the case of organic soils we found little or no effects of soil properties on the $\mathrm{PR}_{\mathrm{SR}}$. The models derived for organic soils use moisture as the only predictor. It is evident that, with a generally lower bulk density and mineral fraction, the influence of oxygenation and clay content become less important. These models serve as a best approximation, but remain rough averages given the limited availability of data and the often incomplete characterization of soil properties. More data of well characterized soils will be needed to better understand moisture effects in these soils.

For mineral soils (with less than $50 \mathrm{mg} \mathrm{Cg}$ soil $^{-1}$ ) the soil factors having an influence on the moisture-respiration relationship involved aeration and structure (bulk density), texture (clay) and composition (carbon content). The models we derived from the data include clay but not silt or sand. This was a result of the large effect of clay and the relatively small influence of silt or sand when including one or the other in the linear regression. This is probably caused by the much larger specific surface area of clay which affects water retention and availability. The increase in the optimum water content for respiration with increasing clay fraction we observed has also been identified in field studies (Balogh et al., 2011). Water potential is the only measure of soil moisture for which this pattern was not observed.

Biological and physical theory predicts that microbial activity in soils should be tightly regulated by the osmotic and matric potential of water (Parr et al., 1981; Orchard and Cook, 1983). Accordingly, the relation between soil respiration and soil water potential $\left(\psi_{\log }\right)$ was the least affected by soil properties. RMSD values (Table 3) show that this measure was the best predictor of respiration rates with or without including soil properties - except in organic soils, which may be the result of having only three related datasets. However, since large changes in water potential are often associated with small changes in water content, predicting water potential in soils could itself be associated with large errors. Among the models based on measures of water content $\left(\theta_{\mathrm{s}}\right.$, $\theta_{\mathrm{m}}$ or $\theta_{\mathrm{v}}$ ), those using $\theta_{\mathrm{s}}$ resulted in the lowest root mean square deviation and were thus the best predictor of respiration rates. Ultimately, finding the measure that performs best in large scale simulations will require a validation of model performance against actual field data. It should be noted that $R^{2}$ were not reported because, first, different models were fit with different sets of observations, and second, even with a low $R^{2}$ a moisture measure may still be a good predictor of respiration, as would be the case of a mostly constant $P R_{S R}$ that does not vary with any of the predictor variables.

The main limitation of our models was simulating the respiration response at low values of moisture, usually associated with less than $10 \% \theta_{\mathrm{s}}$. This was partially the result of the lack of data at low moistures (Fig. 1), but also of the analysis procedure. Because we compared soils with unknown basal respiration rates and incubated under very different conditions, the only comparable measure for this analysis was the proportional or relative change. However, this means that at respiration values approaching 0 this proportional change will tend to increase exponentially, resulting in a wide spread of values and a poor model performance in this range. In this study, we chose to apply a rescaling of predicted values to obtain a zero-intercept (Fig. 3), as described in methods, thus introducing a negative bias but making fluxes at low moisture more realistic. Note that for water potential models this rescaling was not performed.

The data from England and Wales soils used for model comparison represents a large range of properties characteristic of soils in temperate regions. The range of respiration curves we predicted (Fig. 4), related to variations in the properties of these soils, covered most of the differences between strongly differing functions such as those used in the RothC, CANDY and Bethy models. Thus, the variability in model predictions, associated with different moisture functions, can be largely reduced or eliminated by using a common, but generally valid, soil-dependent moisture-respiration function. Depending on the model, soil and climate, significantly different predictions of soil carbon decomposition are expected after including these soil-dependent functions. In most cases this will tend to lower rates of respiration and, consequently, to an increased sequestration of carbon in soils.

Our predictions rely on regression models which are practical and have the advantage of being based on data. As a drawback, they can result in unrealistic values when extrapolating or where data was insufficient or non-linear. This can be avoided by using mechanistic models that integrate, or are parameterized with, the results of empirical studies. A recent study that provides a process based framework of the soil moisture-respiration relationship is that of Davidson et al. (2012). The Dual Arrhenius and Michaelis-Menten kinetics model (DAMM) they describe has the advantage of being process based, so that moisture effects are reproduced by simulating the diffusion of substrates and oxygen depending on water and air space content, respectively. DAMM is, however, in an early stage of development and must be parameterized for individual soils. In this sense, regression models may prove more useful at this stage and for large scale simulations. As mechanistic models incorporate the effects of texture, bulk density, etc., they should reproduce the effects of soil properties in a way that is consistent with the correlations observed here.

\section{Conclusions}

It remains unclear if soils will cause a positive or negative feedback to global warming as global changes in climatic patterns affect soil temperature and moisture (IPCC, 2007; Kendon et al., 2009; Burke and Brown, 2010), but the 
moisture response of soil carbon decomposition will likely have an important role in determining any future evolution. The empirical analysis presented here is a comprehensive synthesis of what has been observed to date. But most importantly, it shows that the soil heterotrophic respiration response to moisture depends on soil properties in a consistent and largely predictable way, explaining a significant part of the variations found across studies. Future studies should concentrate on reducing uncertainties in these relationships and on better representing specific field conditions, such as the depth-dependence of oxygen availability and the dynamics of water in soils. This will require obtaining and analyzing more relevant data while using observed relationships to develop process-based models.

\section{Supplementary material related to this article is available online at: http://www.biogeosciences.net/9/1173/2012/ bg-9-1173-2012-supplement.zip.}

Acknowledgements. This work was supported by the Project Carbosoil from GIS Climat-Environnement-Société. England and Wales soils data were used under licence of "Soils Data (c) Cranfield University (NSRI) and for the Controller of HMSO, 2011”.

Edited by: M. Bahn

\section{References}

Abrahamsen, P. and Hansen, S.: Daisy: an open soil-cropatmosphere system model, Environ. Modell. Softw., 15, 313330, 2000.

Balogh, J., Pintér, K., Fóti, S., Cserhalmi, D., Papp, M., and Nagy, Z.: Dependence of soil respiration on soil moisture, clay content, soil organic matter, and $\mathrm{CO}_{2}$ uptake in dry grasslands, Soil Biol. Biochem., 43, 1006-1013, 2011.

Bauer, J., Herbst, M., Huisman, J., Weihermüller, L., and Vereecken, H.: Sensitivity of simulated soil heterotrophic respiration to temperature and moisture reduction functions, Geoderma, 145, 17-27, 2008.

Bellamy, P. H., Loveland, P. J., Bradley, R. I., Lark, R. M., and Kirk, G. J. D.: Carbon losses from all soils across England and Wales 1978-2003, Nature, 437, 245-248, 2005.

Bowden, R., Newkirk, K., and Rullo, G.: Carbon dioxide and methane fluxes by a forest soil under laboratory-controlled moisture and temperature conditions, Soil Biol. Biochem., 30, 15911597, 1998.

Burke, E. J. and Brown, S. J.: Regional drought over the UK and changes in the future, J. Hydrol., 394, 471-485, 2010.

Coleman, K. and Jenkinson, D. S.: RothC-26.3, A Model for the Turnover of Carbon in Soil: Model Description and User's Guide. Lawes Agric. Trust, Harpenden, UK, 1999.

Cook, F. J. and Orchard, V. A.: Relationships between soil respiration and soil moisture, Soil Biol. Biochem., 40, 1013-1018, 2008.
Cook, F. J., Orchard, V. A., and Corderoy, D. M.: Effects of lime and water content on soil respiration, New Zeal. J. Agr. Res., 28, 517-523, 1985.

Craine, J. M. and Gelderman, T. M.: Soil moisture controls on temperature sensitivity of soil organic carbon decomposition for a mesic grassland, Soil Biol. Biochem., 43, 455-457, 2011.

Curiel Yuste, J., Baldocchi, D. D., Gershenson, A., Goldstein, A., Misson, L., and Wong, S.: Microbial soil respiration and its dependency on carbon inputs, soil temperature and moisture, Global Change Biol., 13, 2018-2035, 2007.

Davidson, E. A. and Janssens, I. A.: Temperature sensitivity of soil carbon decomposition and feedbacks to climate change, Nature, 440, 165-173, 2006.

Davidson, E. A., Verchot, L. V., Cattanio, J. H., Ackerman, I. L., and Carvalho, J. E. M.: Effects of soil water content on soil respiration in forests and cattle pastures of eastern Amazonia, Biogeochem., 48, 53-69, 2000.

Davidson, E. A., Samanta, S., Caramori, S. S., and Savage, K.: The Dual Arrhenius and Michaelis-Menten kinetics model for decomposition of soil organic matter at hourly to seasonal time scales, Global Change Biol., 18, 371-384, 2012.

Doran, J. W.: Microbial activity as regulated by soil water-filled pore space, in: Transactions 14th International Congress of Soil Science. Presented at the 14th International Congress of Soil Science, 12-18 August 1990, Kyoto, Japan, 94-99, 1990.

Falloon, P., Jones, C. D., Ades, M., and Paul, K.: Direct soil moisture controls of future global soil carbon changes: An important source of uncertainty, Global Biogeochem. Cy., 25, GB3010, doi:10.1029/2010GB003938, 2011.

Franko, U., Oelschlagel, B., and Schenk, S.: Modellierung von Bodenprozessen in Agrarlandschaften zur Untersuchung der Auswirkungen möglicher Klimaveränderungen, Sektion Bodenforschung, UFZ-Umweltforschungszentrum Leipzig-Halle GmbH, Leipzig, DE 3, 1995.

Franzluebbers, A. J.: Microbial activity in response to water-filled pore space of variably eroded southern Piedmont soils, Appl. Soil Ecol., 11, 91-101, 1999.

Greaves, J. E. and Carter, E. G.: The influence of moisture and soluble salts on the bacterial activities of the soil, Soil Sci., 13, 251-270, 1922.

Gulledge, J. and Schimel, J. P.: Moisture control over atmospheric $\mathrm{CH}_{4}$ consumption and $\mathrm{CO}_{2}$ production in diverse Alaskan soils, Soil Biol. Biochem., 30, 1127-1132, 1998.

Ilstedt, U., Nordgren, A., and Malmer, A.: Optimum soil water for soil respiration before and after amendment with glucose in humid tropical acrisols and a boreal mor layer, Soil Biol. Biochem. 32, 1591-1599, 2000.

IPCC: Climate Change 2007: The Physical Science Basis. Contribution of Working Group I to the Fourth Assessment Report of the Intergovernmental Panel on Climate Change. Cambridge University Press, Cambridge, United Kingdome and New York, NY, USA, 2007.

Ito, A. and Oikawa, T.: A simulation model of the carbon cycle in land ecosystems (Sim-CYCLE): a description based on drymatter production theory and plot-scale validation, Ecol. Modell., 151, 143-176, 2002

Jassal, R. S., Black, T. A., Novak, M. D., Gaumont-Guay, D., and Nesic, Z.: Effect of soil water stress on soil respiration and its temperature sensitivity in an 18-year-old temperate Douglas-fir 
stand, Global Change Biol., 14, 1305-1318, 2008.

Kendon, E. J., Rowell, D. P., and Jones, R. G.: Mechanisms and reliability of future projected changes in daily precipitation, Clim. Dynam., 35, 489-509, 2009.

Knorr, W.: Annual and Internannual $\mathrm{CO}_{2}$ Exchanges of the Terrestrial Biosphere: Process-Based Simulations and Uncertainties, Global Ecol. Biogeogr., 9, 225-252, 2000.

Linn, D. and Doran, J.: Effect of Water-Filled Pore-Space on Carbon-Dioxide and Nitrous-Oxide Production in Tilled and Nontilled Soils, Soil Sci. Soc. Am. J., 48, 1267-1272, 1984.

Liu, W., Zhang, Z., and Wan, S.: Predominant role of water in regulating soil and microbial respiration and their responses to climate change in a semiarid grassland, Global Change Biol., 15, 184-195, 2009.

Lomander, A., Kätterer, T., and Andrén, O.: Carbon dioxide evolution from top-and subsoil as affected by moisture and constant and fluctuating temperature, Soil Biol. Biochem., 30, $2017-$ 2022, 1998.

Nyhan, J. W.: Influence of soil temperature and water tension on the decomposition rate of carbon-14 labeled herbage, Soil Sci., 121, 288-293, doi:10.1097/00010694-197605000-00005, 1976.

Orchard, V. A. and Cook, F. J.: Relationship between soil respiration and soil-moisture, Soil Biol. Biochem., 15, 447-453, 1983.

Orchard, V. A., Cook, F. J., and Corderoy, D. M.: Field and laboratory studies on the relationship between respiration and moisture for 2 soils of contrasting fertility status, Pedobiologia, 36, 21-33, 1992.

Parr, J. F., Gardner, W. R., and Elliott, L. F.: Water potential relations in soil microbiology, Special Publications 9, Soil Sci. Soc. Am., Madison, WI, USA, 1981.

Paul, K. I., Polglase, P. J., O'Connell, A. M., Carlyle, J. C., Smethurst, P. J., and Khanna, P. K.: Defining the relation between soil water content and net nitrogen mineralization, Eur. J. Soil Sci., 54, 39-48, 2003.

Powlson, D. S., Smith, P., and Smith, J. U.: Evaluation of Soil Organic Matter Models, NATO ASI Series. Series 1: Global Environmental Change, Springer, Berlin, DE, 1996.

Reichstein, M., Subke, J. A., Angeli, A. C., and Tenhunen, J. D.: Does the temperature sensitivity of decomposition of soil organic matter depend upon water content, soil horizon, or incubation time?, Global Change Biol., 11, 1754-1767, 2005.
Rey, A., Petsikos, C., Jarvis, P. G., and Grace, J.: Effect of temperature and moisture on rates of carbon mineralization in a Mediterranean oak forest soil under controlled and field conditions, Eur. J. Soil Sci., 56, 589-599, 2005.

Rodrigo, A., Recous, S., Neel, C., and Mary, B.: Modelling temperature and moisture effects on $\mathrm{C}-\mathrm{N}$ transformations in soils: comparison of nine models, Ecol. Modell., 102, 325-339, 1997.

Rühlmann, J., Körschens, M., and Graefe, J.: A new approach to calculate the particle density of soils considering properties of the soil organic matter and the mineral matrix, Geoderma, 130, 272-283, 2006.

Schjonning, P., Thomsen, I., Moberg, J., de Jonge, H., Kristensen, K., and Christensen, B.: Turnover of organic matter in differently textured soils - I. Physical characteristics of structurally disturbed and intact soils, Geoderma, 89, 177-198, 1999.

Šimunek, J. and Suarez, D. L.: Modeling of carbon dioxide transport and production in soil 1, Model development, Water Resour. Res., 29, 487-497, 1993.

Skopp, J., Jawson, M., and Doran, J.: Steady-state aerobic microbial activity as a function of soil-water content, Soil Sci. Soc. Am. J., 54, 1619-1625, 1990.

Stott, D. E., Elliott, L., Papendick, R., and Campbell, G.: Lowtemperature or low water potential effects on the microbial decomposition of wheat residue, Soil Biol. Biochem., 18, 577-582, 1986.

Thomsen, I., Schjonning, P., Jensen, B., Kristensen, K., and Christensen, B.: Turnover of organic matter in differently textured soils - II, Microbial activity as influenced by soil water regimes, Geoderma, 89, 199-218, 1999.

Vincent, G., Shahriari, A. R., Lucot, E., Badot, P.-M., and Epron, D.: Spatial and seasonal variations in soil respiration in a temperate deciduous forest with fluctuating water table, Soil Biol Biochem., 38, 2527-2535, 2006.

Wickland, K. P. and Neff, J. C.: Decomposition of soil organic matter from boreal black spruce forest: environmental and chemical controls, Biogeochem., 87, 29-47, 2008. 